\title{
KILAT
}

Vol. 10, No. 1, April 2021, P-ISSN 2089-1245, E-ISSN 2655-4925

DOI: https://doi.org/10.33322/kilat.v10i1.1161

\section{Penerapan Semi-Immersion Virtual Reality Untuk Simulasi Instalasi Transmisi Listrik}

\author{
Muhammad Fadli Prathama ${ }^{1}$; Andi Dahroni ${ }^{2}$ Pritasari Palupi Ningsih ${ }^{3}$ \\ 1, 2, ${ }^{3}$ Institut Teknologi PLN \\ ${ }^{1}$ fadli@itpln.ac.id \\ 2 andidahroni@itpln.ac.id \\ 3 pritasari@itpln.ac.id
}

\begin{abstract}
Increasing the use of electricity every year always occurs, as well as an increase in the construction of substations and distribution substations as a means of PLN electricity transmission. The process of maintaining and installing substations and distribution substations certainly has a very high risk that can sometimes be deadly. The workers who are going to perform maintenance and installation of the electricity network require qualifications to work at a place that is at a height. These qualifications make Electrical Engineering students have a lesson about the installation of electricity networks where they will try to climb the electricity poles to do the electrical network installation. For that we need an application that can use virtual reality technology so that students and students can learn the process of installing the electricity network more safely, before they go straight into the field. This application was created using Unity 2019 software, which can produce mobile-based programs both in the android operating system. This research will use MDLC method for multimedia software development and 360 video with semiimmersion approach which will illustrate how the process of climbing to the top of the electricity pole and the process of installing the electricity network. This study aims to build a simulation application of electrical network installation using virtual reality technology, which is expected to provide an overview and simulation for Electrical Engineering students so that the learning process is safer and more controlled.
\end{abstract}

Keywords: Virtual reality, semi-immersion, simulation, altitude, electricity network

\begin{abstract}
ABSTRAK
Peningkatan penggunaan listrik setiap tahun selalu terjadi, begitu pula dengan peningkatan pembangunan gardu induk dan gardu distribusi sebagai sarana transmisi listrik PLN. Proses perawatan maupun instalasi gardu induk dan gardu distribusi tersebut tentunya memiliki resiko yang sangat tinggi yang kadang bisa mematikan. Para pekerja yang akan melakukan perawatan maupun instalasi jaringan listrik memerlukan kualifikasi untuk bekerja pada tempat yang berada pada ketinggian. Kualifikasi tersebut membuat mahasiswa Teknik Elektro memiliki pelajaran tentang praktikum instalasi jaringan listrik dimana mereka akan mencoba menaiki tiang listrik untuk melakukan instalasi jaringan listrik. Untuk itu diperlukan suatu aplikasi yang dapat menggunakan teknologi virtual reality sehingga pelajar maupun mahasiswa dapat mempelajari proses instalasi jaringan listrik dengan lebih aman, sebelum mereka terjun langsung ke lapangan. Aplikasi ini dibuat dengan menggunakan software Unity 2019, yang dapat menghasilkan program berbasis mobile baik itu dalam operasi sistem android. Penelitian ini akan menggunakan metode MDLC untuk pengembangan aplikasi multimedia serta video 360 dengan pendekatan semi-immersion yang akan menggambarkan bagaimana proses naik ke atas tiang listrik dan proses instalasi jaringan listrik. Penelitian ini bertujuan untuk membangun aplikasi simulasi instalasi jaringan listrik menggunakan teknologi virtual reality, agar dapat memberikan gambaran dan simulasi untuk mahasiswa Teknik Elektro agar proses pembelajaran lebih aman dan terkendali.
\end{abstract}

Kata kunci: Virtual reality, semi-immersion, simulasi, ketinggian, jaringan listrik 


\section{PENDAHULUAN}

Peningkatan penggunaan listrik setiap tahunnya selalu terjadi, begitu pula dengan peningkatan pembangunan gardu [1] induk dan gardu distribusi sebagai sarana transmisi listrik PLN. Berdasarkan Laporan Statistik PLN 2019 [2] yang dikeluarkan PLN dibawah Direktorat Jenderal Ketenagalistrikan Kementerian Energi dan Sumber Daya Mineral, menerangkan bawah jumlah gardu induk pada tahun 2019 adalah sebanyak 1.742, naik dari 1.573 pada tahun sebelumnya. Begitu juga dengan gardu distribusi yang mengalami kenaikan dari 433.511 pada tahun 2018 ke 471.765 pada tahun 2019. Proses perawatan maupun instalasi gardu induk dan gardu distribusi tersebut tentunya memiliki resiko yang sangat tinggi [3]. Kecelakaan yang bisa terjadi pada saat naik ke atas tiang listrik maupun pada saat instalasi bisa mematikan. Sangat penting agar para pegawai maupun pekerja yang akan melakukan instalasi adalah mereka yang memiliki keahlian yang tinggi [4], agar tugas yang dilakukan akan lebih aman dan lebih efisien dalam lingkungan kerja yang berbahaya tersebut. [5]

Para pekerja yang akan melakukan perawatan maupun instalasi jaringan listrik memerlukan kualifikasi untuk bekerja pada tempat yang berada pada ketinggian, karena beberapa gardu distribusi berada pada tempat tinggi Kualifikasi tersebut membuat pelajar mahasiswa Teknik Elektro memiliki pelajaran tentang praktikum instalasi jaringan listrik dimana mereka akan mencoba menaiki tiang listrik untuk melakukan instalasi jaringan listrik. Hal ini tentu akan mengancam keselamatan terutama yang memiliki Acrophobia [6].

Virtual Reality (VR) merupakan penggunaan sistem komputer grafik yang dikombinasikan dengan beragam tampilan untuk menyediakan efek masuk ke dalam lingkungan interaktif digital 3D dalam komputer [7]. Virtual Reality yang digunakan pada penelitian ini akan berupa SemiImmersion Virtual Reality yang menggunakan perangkat smartphone yang akan ditempelkan pada Google Cardboard agar pengguna dapat merasakan sensasi simulasi secara langsung dan naik ke atas tiang instalasi jaringan listrik. Dengan pendekatan semi-immersion, pengguna diharapkan dapat masuk ke dunia simulasi virtual dan dapat merasakan pengalaman [8] menaiki tiang listrik dan mempelajari cara instalasi listrik secara virtual. Pembelajaran dengan menggunakan teknologi virtual reality dapat memberikan jaminan keamanan terutama untuk para pelajar/mahasiswa yang belum memiliki pengalaman untuk naik ke atas tiang listrik. Pertama, kami menggunakan metode MDLC untuk pengembangan aplikasi yang menggunakan video 360 yang akan menggambarkan [9] bagaimana proses naik ke atas tiang listrik dan proses instalasi jaringan listrik. Kami kemudian akan menggabungkannya dengan resiko-resiko yang akan muncul pada saat melakukan instalasi, sehingga pengguna dapat belajar dan memahami bagaimana penanggulangannya. Hal ini dilakukan untuk memberikan gambaran dan pembelajaran awal kepada pelajar dan mahasiswa [10], sehingga pada saat praktikum langsung di lapangan tidak kaget dan panik dan dapat mengurangi resiko kecelakaan. Untuk itu, diperlukan aplikasi yang dapat digunakan untuk melakukan simulasi tentang praktik lapangan instalasi jaringan listrik. [11] Sistem ini dapat dimanfaatkan mahasiswa Teknik Elektro untuk mensimulasikan [9] proses instalasi jaringan listrik, sehingga mereka dapat mendapatkan pengalaman sebelum masuk ke praktek di lapangan. Penelitian ini bertujuan untuk membangun aplikasi simulasi instalasi jaringan listrik menggunakan teknologi virtual reality. 


\section{KILAT}

Vol. 10, No. 1, April 2021, P-ISSN 2089-1245, E-ISSN 2655-4925

DOI: https://doi.org/10.33322/kilat.v10i1.1161

\section{METODE PENELITIAN}

\subsection{Semi-Immersive Virtual Reality}

Semi-immersive virtual reality [9] mengacu pada jenis VR tertentu yang memungkinkan pengguna untuk mengalami lingkungan tiga dimensi virtual sementara tetap terhubung ke dunia nyata di sekitar visual, auditori, penciuman, dan haptik serta menjaga kontrol atas objek fisik. Dengan semi-immersive VR, Anda dapat melihat apa yang terjadi di sekitar Anda dan berinteraksi dengan objek yang Anda butuhkan. Namun, untuk mendapatkan perendaman setinggi mungkin, Anda harus fokus pada gambar digital. [12]

\subsection{Multimedia Development Life Cycle}

Metode pengembangan aplikasi yang digunakan pada penelitian ini adalah MDLC (Multimedia Development Life Cycle) [13] yang didalamnya terdapat 6 tahapan, yaitu concept, design, material collecting, assembly, testing dan distribution. [14]

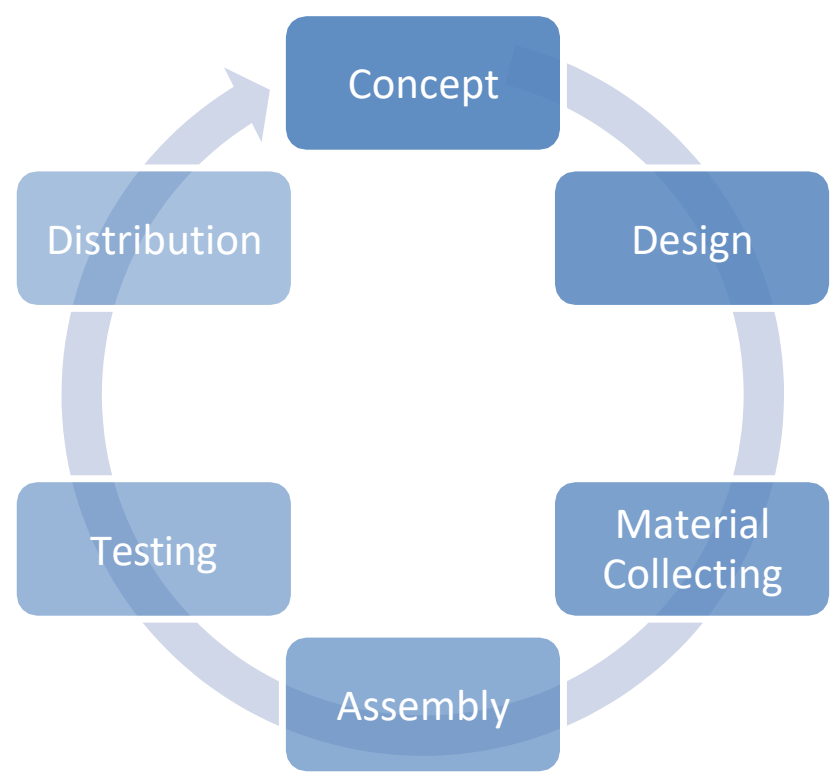

Gambar 1. Multimedia Development Life Cycle [14]

a. Concept (Pengonsepan)

Tahapan ini digunakan untuk menentukan tujuan serta siapa pemakai program (identification audience), tujuan aplikasi, jenis aplikasi, dan spesifikasi umum. Dasar aturan yang dipakai perancangan juga ditentukan pada tahap ini, seperti ukuran target, aplikasi, dan lain-lain.

b. Design (Perancagan)

Design merupakan tahapan yang melakukan spesifikasi secara rinci mengenai arsitektur aplikasi, tampilan, gaya dan kebutuhan meterial/bahan untuk pembuatan aplikasi.

c. Material Collecting (Pengumpulan bahan)

Tahapan ini melakukan pengumpulan bahan yang sesuai dengan kebutuhan yang dikerjakan. Bahan-bahan yang digunakan seperti gambar foto, clip art, video, animasi, audio, dan lainnya yang bisa didapatkan secara gratis atau dengan membeli kepada pihak lain sesuai dengan rancangannya. Tahap ini dapat dikerjakan secara paralel dengan tahap assembly. 
d. Assembly (Pembuatan)

Tahap ini merupakan tahap dimana semua objek atau bahan multimedia dibuat menjadi sebuah aplikasi. Pembuatan aplikasi berdasarkan bagan alir, storyboard, dan struktur navigasi yang berasal pada tahap design.

e. Testing (Pengujian)

Setelah aplikasi dibuat maka saatnya untuk tahap uji kinerja dan kemampuan dari aplikasi tersebut, apakah sudah layak dengan yang diharapkan. Disini dilihat kembali (recompile) apakah semua tombol, link, dan fitur-fitur lainnya dapat berfungsi dengan baik

f. Distribution (Pendistribusian)

Pada tahap ini merupakan tahap aplikasi akan disimpan dalam suatu media penyimpanan, tahap ini juga bisa disebut tahap evaluasi untuk pengembangan produk yang sudah jadi

\section{a. Concept}

Aplikasi yang dibuat dalam penelitian ini bertujuan untuk membuat simulasi instalasi jaringan listrik distribusi berbasis Virtual Reality (VR). Tahapan ini menghasilkan rumusan konsep yaitu:

Tabel 1. Rumusan konsep

\begin{tabular}{|c|c|}
\hline Kategori & Hasil / Tujuan \\
\hline Pengguna & Mahasiswa dan dosen D3 Teknik Elektro \\
\hline Animation & Video $360^{\circ}(* . M P 4)$ \\
\hline Audio & Voice changer $(* . M P 3)$ \\
\hline Image & Image,Icon,Button (*.PNG dan *.JPG) \\
\hline Tema & Virtual Reality \\
\hline OS Minimum & Android Kitkat (4.4) \\
\hline Deskripsi Aplikasi & $\begin{array}{l}\text { Game ini merupakan sebuah game berbasis } \\
\text { Simulasi Virtual Reality dimana pengguna } \\
\text { bisa melihat area sekitar pada proses } \\
\text { Praktikum sedang berlangsung }\end{array}$ \\
\hline
\end{tabular}

\section{b. Design}

Pada tahapan design memerlukan storyboard, storyboard digunakan untuk menggambarkan alur perancangan desain tampilan aplikasi Virtual Reality dan menggambarkan deskripsi tiap scene.

Tabel 2. Storyboard

\begin{tabular}{|c|c|}
\hline Scene & Deskripsi \\
\hline 1 & $\begin{array}{l}\text { Tampilan Awal Aplikasi akan menampilkan menu start, scene, instruction, } \\
\text { dan exit. }\end{array}$ \\
\hline 2 & $\begin{array}{l}\text { Tampilan menu scene akan menampilkan } 5 \text { button pilihan scene, beserta } \\
\text { button kembali. }\end{array}$ \\
\hline 3 & $\begin{array}{l}\text { Tampilan menu instruction akan menampilkan petunjuk cara pemakain } \\
\text { atau penggunaan aplikasi. }\end{array}$ \\
\hline $4,5,6,7,8$ & $\begin{array}{l}\text { Tampilan menu gameplay semua sama persis tetapi yang membedakan } \\
\text { hanya isi dari menu info. }\end{array}$ \\
\hline
\end{tabular}




\section{KILAT}

Vol. 10, No. 1, April 2021, P-ISSN 2089-1245, E-ISSN 2655-4925

DOI: https://doi.org/10.33322/kilat.v10i1.1161

\begin{tabular}{|c|l|}
\hline $\mathbf{5}$ & $\begin{array}{l}\text { Tampilan menu info terdapat text,2 button diantara nya untuk close menu } \\
\text { info dan button navigasi untuk melanjutkan teks. }\end{array}$ \\
\hline $\mathbf{6}$ & Tampilan menu pause terdapat 3 button yaitu restart,menu,exit \\
\hline
\end{tabular}

Selanjutnya adalah tampilan design aplikasi yang akan dibuat. Berikut adalah tampilan aplikasinya.

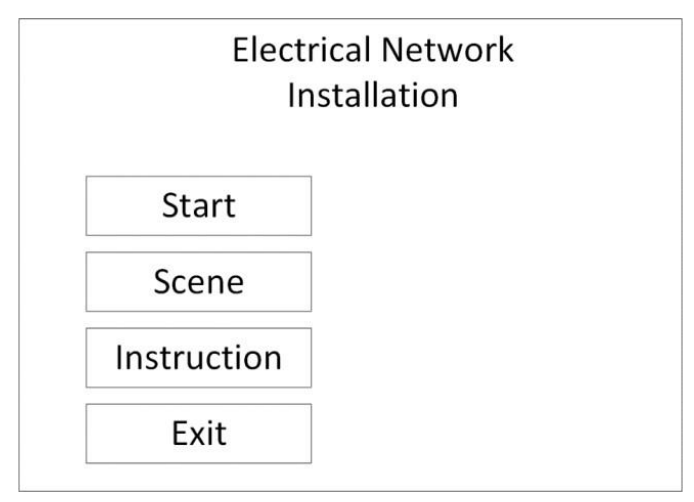

Gambar 2. Desain Menu Utama

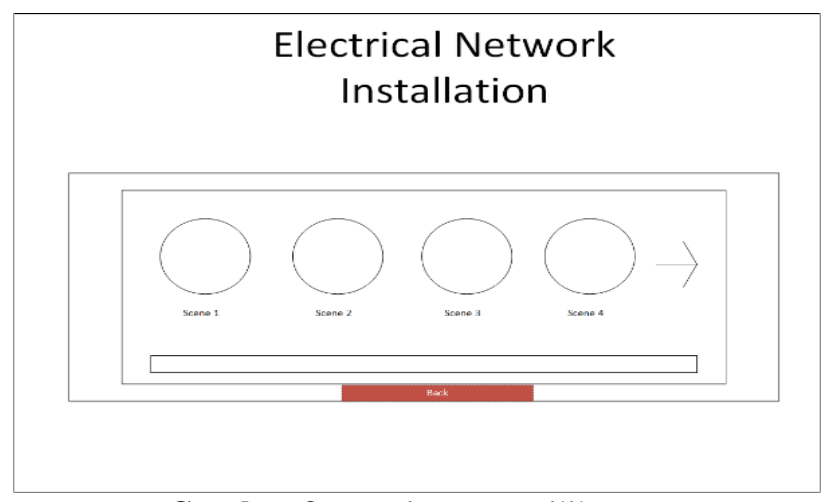

Gambar 3. Desain Menu Pilihan

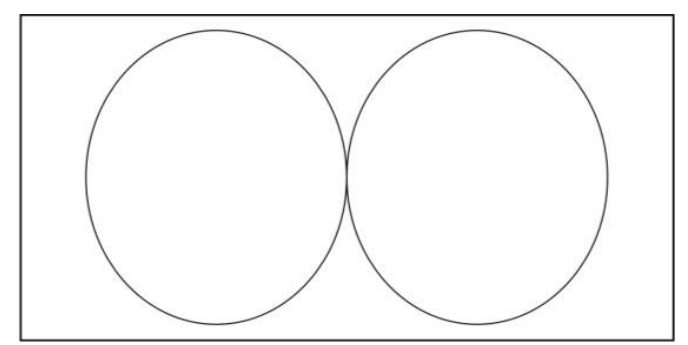

Gambar 4. Desain Gameplay

\section{c. Material Collecting}

Pada tahap ini merupakan proses untuk pengumpulan segala sesuatu yang dibutuhkan dalam perencanaan merancang. Adapun objek yang dipakai sebagai berikut adalah.

1. Image

2. Sound

3. Video

\section{d. Assembly}

Tahap assembly (pembuatan) merupakan tahap semua objek atau bahan yang telah 
dikumpulkan kemudian dirangkai dan disusun, dimana pembuatan didasarkan pada tahap design. Tahap pembuatan aplikasi menggunakan unity versi 2018. Pada tahap pertama dalam assembly yaitu membuat sebuah main menu 2D. Berikut ini akan dijelaskan gambaran dan detail objek yang dipakai

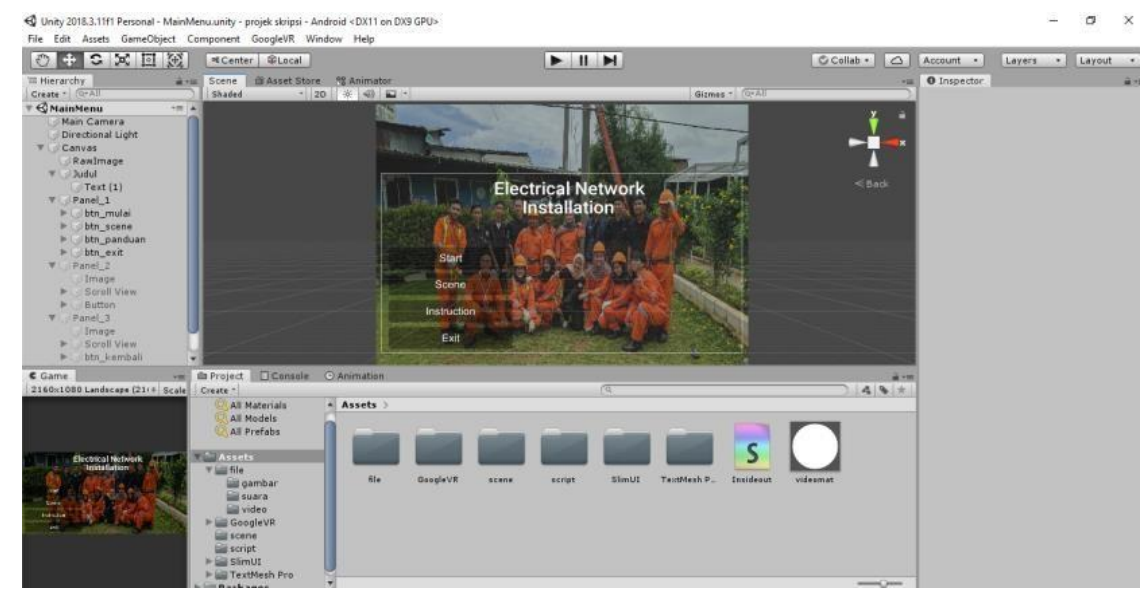

Gambar 5. Pembuatan Main Menu

Gambar diatas menjelaskan bahwa, untuk membuat sebuah scene main menu terdapat sebuah foto saat praktikum sebagai background main menu, lalu terdapat 4 button dimana terdiri dari: start, scene, instruction, dan exit. Lalu tahap assembly selanjutnya yaitu pembuatan scene gameplay. Berikut ini akan dijelaskan gambaran dan detail objek yang dipakai :

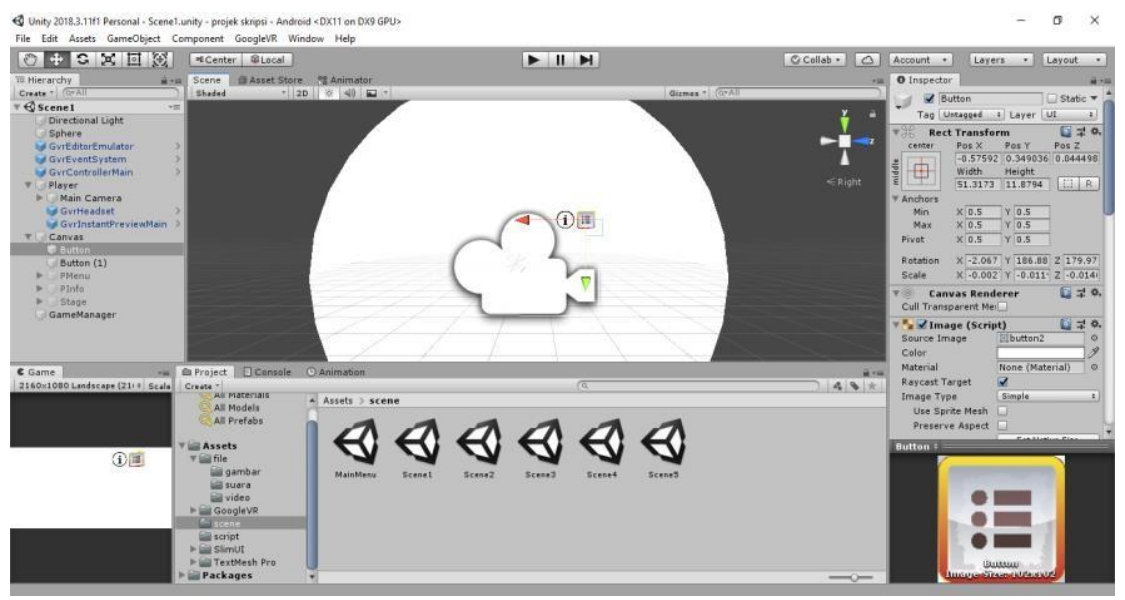

Gambar 6. Pembuatan Scene Gameplay

Gambar diatas menjelaskan bahwa terdapat sebuah objek sphere untuk menampung atau menjalankan sebuah video virtual reality yang telah ada dan ada objek button 3D yang berfungsi untuk ke menu info dan menu pause. Pada objek sphere ditambahkan sebuah package google virtual reality lalu di import ke objek sphere dan main camera. Lalu pada gambar diatas pada player settings dibagian xr settings di tambahkan list none dan cardboard. 


\section{KILAT}

Vol. 10, No. 1, April 2021, P-ISSN 2089-1245, E-ISSN 2655-4925

DOI: https://doi.org/10.33322/kilat.v10i1.1161

\section{e. Testing}

Pada tahap testing (pengujian) ini menggunakan metode UAT [15]. Metode ini menyajikan kuisioner terkait aplikasi yang dibuat dan disebarkan ke pada pengguna aplikasi. Pengujian ini menghasilkan nilai bobot setiap tanggapan yang ditentukan poin perjawaban (Sangat: Mudah/Bagus/Sesuai/Jelas, Mudah/Bagus/Sesuai/Jelas, Netral/Cukup, Cukup: Sulit/Bagus/Sesuai/Jelas, Sangat: Sulit/Jelek/Tidak Sesuai/Tidak Jelas) kemudian poin tiap pertanyaan akan dijumlahkan. Jumlah poin tersebut akan digunakan untuk menentukan angka kategori yang dihitung sehingga nilai tersebut dapat menunjukkan kelayakan dari aplikasi ini. Untuk penjabaran lebih lanjut akan dibahas pada pengujian sistem.

\section{f. Distribution}

Dalam tahapan ini,aplikasi yang telah diuji dan dinyatakan layak dan sesuai dengan tujuan perancangan,akan didistribusikan / dipublikasi dengan format file *.apk yang akan berbentuk link google drive.

\section{HASIL DAN PEMBAHASAN}

\subsection{Hasil Tampilan Main Menu}

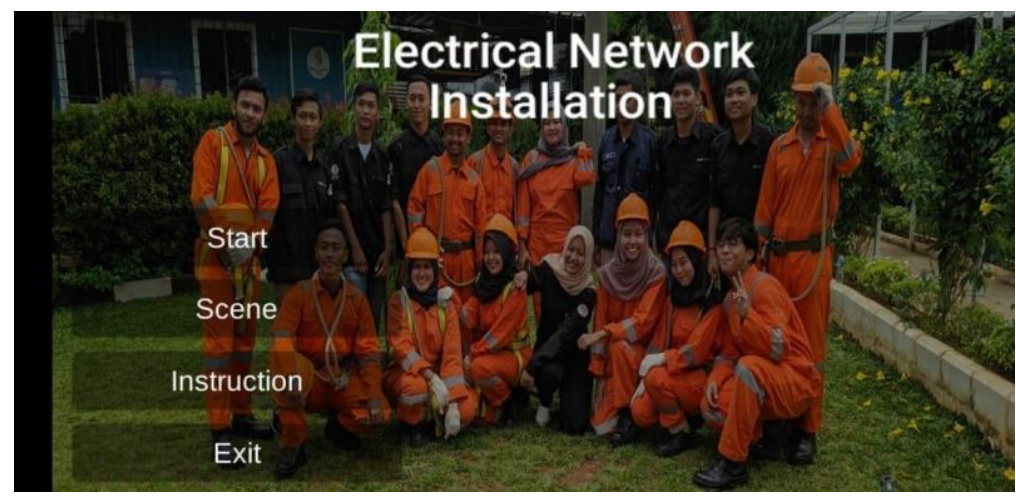

Gambar 7. Tampilan Main Menu

Pada halaman main menu terdapat sebuah button start,scene,instruction, dan exit. Dimana fungsi dari button start merupakan tombol yang akan mengarahkan langsung ke gameplay di scene 1, lalu untuk button scene merupakan tombol yang akan menampilkan menu pilihan scene, selanjutnya button instruction adalah tombol yang akan menampilkan menu petunjuk pemakaian aplikasi ini,dan terakhir button exit dimana tombol ini akan melakukan keluar dari game.Hasil Tampilan Scene

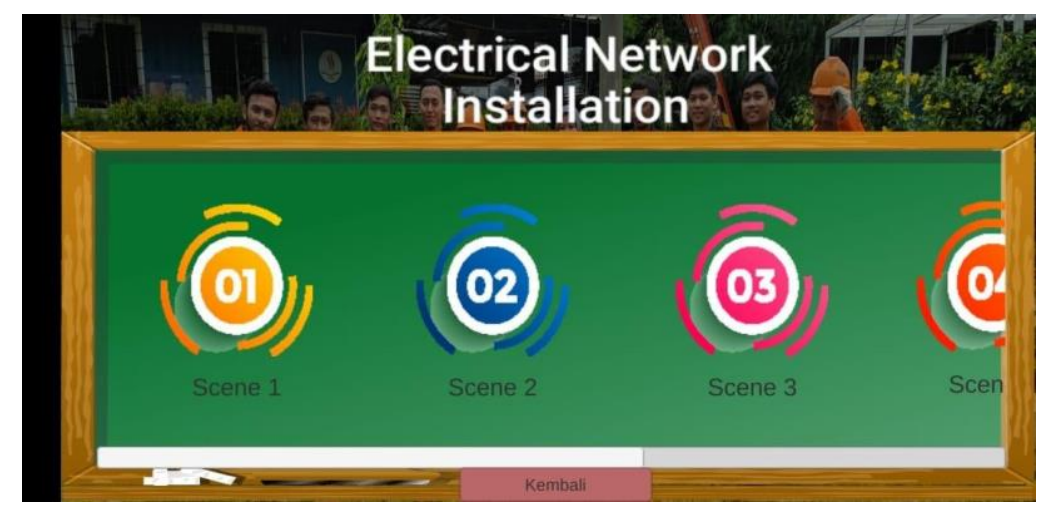

Gambar 8. Tampilan Menu Scene 
Pada halaman ini merupakan tampilan setelah menekan button scene. Halaman ini menampilkan 5 pilihan button scene dimana terdapat fitur scroll ke bagian kiri dan kanan.

\subsection{Hasil Tampilan Gameplay}

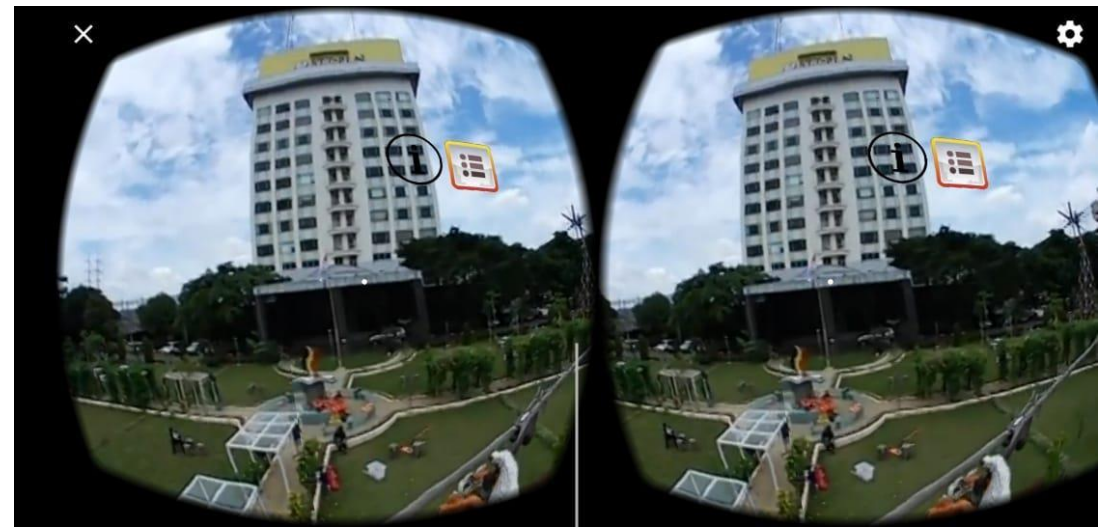

Gambar 9. Tampilan Gameplay 5

Pada halaman ini merupakan gameplay dimana menceritakan proses setelah melakukan maintenance praktikan yang menaiki tiang bersiap menurunkan alat pada gameplay ini masih atau sama dengan fitur yang digunakan hanya saja yang membedakan di bagian menu info dikarenakan jalan cerita di gameplay berbeda

\section{PENGUJIAN}

Pengujian sistem digunakan untuk menjamin kualitas dan juga mengetahui kelemahan dari perangkat lunak.pengujian yang telah dilakukan adalah sebagai berikut:

Tabel 3. Tabel Kuisioner

\begin{tabular}{|c|l|c|c|c|c|c|c|c|c|c|c|}
\hline No & \multicolumn{1}{|c|}{ Pertanyaan } & \multicolumn{5}{|c|}{ Jawaban } & \multicolumn{7}{c|}{ Persentase } \\
\cline { 2 - 10 } & A & B & C & D & E & A & B & C & D & E \\
\hline 1 & $\begin{array}{l}\text { Apakah tampilan } \\
\text { pada aplikasi ini } \\
\text { menarik ? }\end{array}$ & 0 & 8 & 3 & 4 & 0 & $0 \%$ & $52,8 \%$ & $19,8 \%$ & $26,4 \%$ & $0 \%$ \\
\hline 2 & $\begin{array}{l}\text { Apakah menu- } \\
\text { menu di aplikasi } \\
\text { ini mudah } \\
\text { dipahami ? }\end{array}$ & 3 & 5 & 6 & 1 & 0 & $19,8 \%$ & $33 \%$ & 39,6 & $6,6 \%$ & $0 \%$ \\
\hline 3 & $\begin{array}{l}\text { Apakah aplikasi } \\
\text { ini membantu } \\
\text { dalam proses } \\
\text { workshop atau } \\
\text { pembelajaran } \\
\text { instalasi distribusi } \\
\text { jaringan? }\end{array}$ \\
\hline
\end{tabular}




\section{KILAT}

Vol. 10, No. 1, April 2021, P-ISSN 2089-1245, E-ISSN 2655-4925

DOI: https://doi.org/10.33322/kilat.v10i1.1161

\begin{tabular}{|c|c|c|c|c|c|c|c|c|c|c|c|}
\hline 4 & $\begin{array}{l}\text { Apakah kualitas } \\
\text { gambar yang } \\
\text { ditampilkan sesuai } \\
\text { dengan yang di } \\
\text { inginkan? }\end{array}$ & 0 & 8 & & 1 & 0 & $0 \%$ & $52,8 \%$ & 39,6 & $6,6 \%$ & $0 \%$ \\
\hline 5 & $\begin{array}{l}\text { Bagaimana } \\
\text { menurut anda } \\
\text { tentang waktu } \\
\text { yang dibutuhkan } \\
\text { ketika aplikasi ini } \\
\text { dijalankan? }\end{array}$ & 6 & 8 & & 1 & 0 & $39,6 \%$ & $52,8 \%$ & $0 \%$ & $6,6 \%$ & $0 \%$ \\
\hline 6 & $\begin{array}{l}\text { Sejauh mana anda } \\
\text { memahami } \\
\text { aplikasi ini? }\end{array}$ & 0 & 8 & 6 & & 0 & $0 \%$ & $52,8 \%$ & $39,6 \%$ & $6,6 \%$ & $0 \%$ \\
\hline 7 & $\begin{array}{l}\text { Apakah tombol } \\
\text { dan tulisan pada } \\
\text { aplikasi ini sudah } \\
\text { tepat? }\end{array}$ & 0 & 8 & 6 & 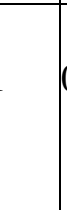 & 0 & $0 \%$ & $52,8 \%$ & $39,6 \%$ & $6,6 \%$ & $0 \%$ \\
\hline 8 & $\begin{array}{l}\text { Bagaimana } \\
\text { dengan kesesuaian } \\
\text { tombol dan fungsi } \\
\text { aplikasi ini apakah } \\
\text { sudah sesuai? }\end{array}$ & 0 & 8 & 6 & & 0 & $0 \%$ & $52,8 \%$ & $39,6 \%$ & $6,6 \%$ & $0 \%$ \\
\hline 9 & $\begin{array}{l}\text { Bagaimana } \\
\text { kenyamanan untuk } \\
\text { penggunaan } \\
\text { aplikasi ini? }\end{array}$ & 0 & 11 & 3 & & 0 & $0 \%$ & $66,6 \%$ & $19,8 \%$ & $6,6 \%$ & $0 \%$ \\
\hline 10 & $\begin{array}{l}\text { Apa pendapat } \\
\text { anda tentang } \\
\text { keseluruhan } \\
\text { aplikasi ini? }\end{array}$ & 0 & 8 & 6 & 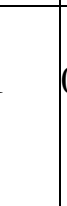 & 0 & $0 \%$ & $52,8 \%$ & $39,6 \%$ & $6,6 \%$ & $0 \%$ \\
\hline
\end{tabular}

Prosentase nilai pada kuisioner tersebut adalah $69,2 \%$. Nilai ini merupakan rata-rata untuk seluruh pertanyaan tesebut. 


\section{KESIMPULAN DAN SARAN}

Aplikasi simulasi ini menggunakan metode semi-immersion dengan menggunakan video 360 untuk semua scene yang ada. Hal ini dilakukan untuk memberikan gambaran lebih real terhadap kejadian sesungguhnya pada saat melakukan praktikum instalasi jaringan listrik. Pada aplikasi ini dilakukan testing kepada 15 responden praktikan, dengan hasil nilai rata-rata 69,2\%.

\section{DAFTAR PUSTAKA}

[1] D. Saefulloh, "Perencanaan pengembangan gardu induk untuk 10 tahun ke depan," Teknik Elektro Universitas Diponegoro, pp. 1-8, 2013. URL: eprints.undip.ac.id/25821/1/ML2F000593.pdf.

[2] P. PLN (Persero), "Statistik PLN 2019," PLN, Jakarta, 2020. URL: https://web.pln.co.id/statics/uploads/2020/11/Statistik-Indonesia-2019.pdf.

[3] A. Ayala García, I. Galván Bobadilla, G. Arroyo Figueroa, M. Pérez Ramírez dan J. Muñoz Román, "Virtual reality training system for maintenance and operation of highvoltage overhead power lines," Virtual Reality, p. 27-40. , 2016. DOI: 10.1007/s10055-015-0280-6.

[4] Tim K3 FT UNY, "Buku Ajar Keselamatan Dan Kesehatan Kerja (K3)," Keselamatan da Kesehatan kerja (k3), p. 163, 2014. URL: https://www.mendeley.com/catalogue/07a2e182bfdf-35f2-9151-47811303640f/.

[5] P. N. A. Barata, M. R. Filho dan M. V. Nunes, "Consolidating learning in power systems: Virtual reality applied to the study of the operation of electric power transformers," IEEE $\begin{array}{lllll}\text { Transactions on } & \text { Education, } 2015 . & \text { DOI: }\end{array}$ https://doi.org/10.1109/TE.2015.2393842.

[6] M. F. Prathama, D. Kuswardani dan A. Dahroni, "PERANCANGAN VIRTUAL REALITY DALAM MENGETAHUI GEJALA ACROPHOBIA,” PETIR, vol. 12, no. 1, pp. 93-100, 2019.

[7] Z. Pan, A. D. Cheok, H. Yang, J. Zhu dan J. Shi, "Virtual reality and mixed reality," Computers and Graphics (Pergamon), p. 20-28, 2006. DOI: https://doi.org/10.1016/j.cag.2005.10.004.

[8] M. Kyriakou, X. Pan dan Y. Chrysanthou, "Interaction with virtual crowd in Immersive and semi-Immersive Virtual Reality systems," Computer Animation and Virtual Worlds, vol. 28, no. 5, 2017.

[9] M. Suryani, E. Paulus dan R. Farabi, "Semi-Immersive Virtual Reality untuk Meningkatkan Motivasi dan Kemampuan Kognitif Siswa dalam Pembelajaran,” dalam Conference: Seminar Nasional Pendidikan Teknk Informatika Ke-7, Denpasar, Bali, 2016.

[10] A. Bustillo, M. Alaguero, I. Miguel, J. M. Saiz dan L. S. Iglesias, "A flexible platform for the creation of 3D semi-immersive environments to teach Cultural Heritage," Digital Applications in Archaeology and Cultural Heritage, p. 248-259, 2015. DOI: https://doi.org/10.1016/j.daach.2015.11.002.

[11] J. Susilo, S. Anitah dan S. Yamtinah, "Pengembangan Media Pembelajaran Virtual dan Interaktif untuk Mensimulasikan Instalasi Jaringan Listrik di SMK 2 Surakarta," dalam Prosiding Seminar Pendidikan Nasional, Surakarta, 2019. URL: http://www.jurnal.fkip.uns.ac.id/index.php/psdtp/article/view/10432/7621.

[12] V. TSYKTOR, "What Is Semi-Immersive Virtual Reality? - CyberPulse," CyberPulse, 232 2019. [Online]. Available: https://cyberpulse.info/what-is-semi-immersive-virtual-reality/. [Diakses 246 2020].

[13] D. Nurdiana dan A. Suryadi, "PERANCANGAN GAME BUDAYAKU INDONESIAKU MENGGUNAKAN METODE MDLC," JURNAL PETIK, vol. 39, p. 3(2), 2018. DOI: 


\section{KILAT}

Vol. 10, No. 1, April 2021, P-ISSN 2089-1245, E-ISSN 2655-4925

DOI: https://doi.org/10.33322/kilat.v10i1.1161

10.31980/jpetik.v3i2.149.

[14] M. Mustika, E. P. A. Sugara dan M. Pratiwi, "Pengembangan Media Pembelajaran Interaktif dengan Menggunakan Metode Multimedia Development Life Cycle," Jurnal Online Informatika, vol. 2, no. 2, p. 121, 2017 DOI: https://doi.org/10.15575/join.v2i2.139.

[15] I. Otaduy dan O. Diaz, "User acceptance testing for Agile-developed web-based applications: Empowering customers through wikis and mind maps," Journal of Systems and Software, 2017. DOI: 10.1016/j.jss.2017.01.002. 